\title{
RFID and IOT for Attendance Monitoring System
}

\author{
Joseph Dedy Irawan ${ }^{1, *}$, Emmalia Adriantantri ${ }^{2}$, and Akh Farid $^{1}$ \\ ${ }^{1}$ Informatics, National Institute of Technology, Raya Karanglo Km.2 Malang 65153, Indonesia \\ ${ }^{2}$ Industrial Engineering, National Institute of Technology, Raya Karanglo Km.2 Malang 65153, \\ Indonesia
}

\begin{abstract}
In recent years, RFID technology has been widely used in various sectors, such as in-education, transportation, agriculture, animal husbandry, store sales and other sectors. RFID utilization in education is student attendance monitoring system, by using Internet of Things (IoT) and Cloud technology, it will produce a real time attendance monitoring system that can be accessed by various parties, such as lecturer, campus administration and parents. With this monitoring system if there are students who are not present can be immediately discovered and can be taken immediate action and the learning process can run smoothly.
\end{abstract}

Key words: Attendance monitoring system, internet of things, RFID

\section{Introduction}

One of the factors that support the success of the learning system is the presence of students, because if students are often absent then the material they received becomes less and can't understand the material that has been taught, one that causes the absence of students is they ditch, so the attendance monitoring system becomes very important because with this process the attendance of students can be monitored properly.

Various kinds of presences can be used from manual way to automatic way using electronic equipment, if the monitoring system attendance using electronic equipment so the recording of attendance data becomes easier, fast and accurate. In this research, attendance monitoring system using RFID technology and with the application of Internet of Things (IoT) and cloud technology will be obtained a presence system that can run and monitored in real time, so that all parties who need information such as lecturers, parents, and energy the administration can immediately find out if there are students who skip classroom, it can immediately be prevented so that the next meeting does not ditch again.

* Corresponding author: joseph@1ecturer.itn.ac.id 


\section{Materials and methodology}

\subsection{Radio-frequency identification (RFID)}

RFID has grown rapidly in recent decades [1] along with the demand from modern industry where data accuracy is required and efficiency improvements of a system, the supporting components of this electronic equipment are RFID reader and RFID Tags, where many kinds of tags have been manufactured according to industry needs. This technology has been applied to various sectors such as industry [2], airports [3], attendance monitoring systems [4-8], and with the use of IoT will be able to make this system more optimal [9$11]$.

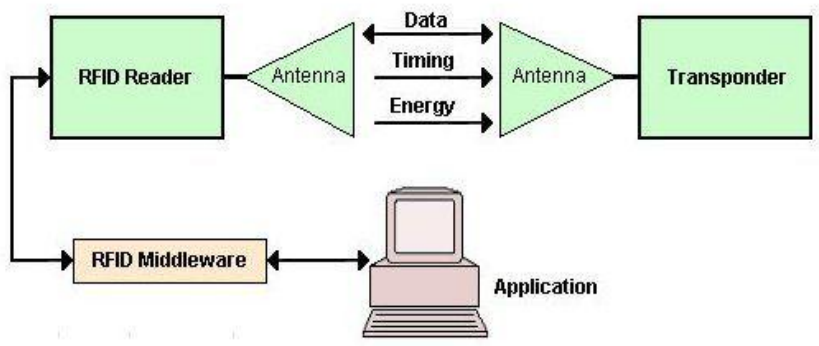

Fig. 1. Components of an RFID system [1].

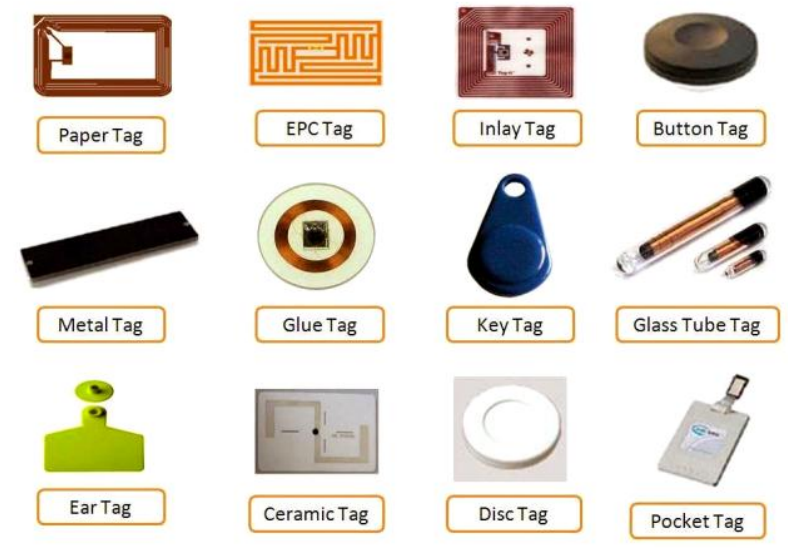

Fig. 2. Type of an RFID tags.

\subsection{Attendance technology}

\subsubsection{Barcode}

In this technology, students carry barcodes printed on their student cards, which at the time of presenting barcodes read using barcode reader, this presence is fast enough and does not cost a fortune, but this system has a drawback where barcodes can be easily duplicated by printed using a regular printer. 


\subsubsection{Magnetic Stripe}

The use of magnetic strips can eliminate the deficiencies of barcodes, because in this technology magnetic card is required as an ID for each student, in the duplication of the magnetic card cannot be done easily because it requires a magnetic card reader and magnetic card writer, which because of the price quite expensive so it cannot be easily owned by students.

\subsubsection{Biometric}

The use of presences using biometric is an excellent solution, because as the ID of each student can be a finger print, retina, or face recognition. However, it has to consider the price of this equipment is very expensive.

Radio Frequency Identification (RFID) attendance monitoring system using RFID is highly recommended, because the required equipment is relatively cheap and the attendance process is very fast, so to make a monitoring system presence with this equipment can save time and budged.

\subsection{Attendance monitoring system with RFID}

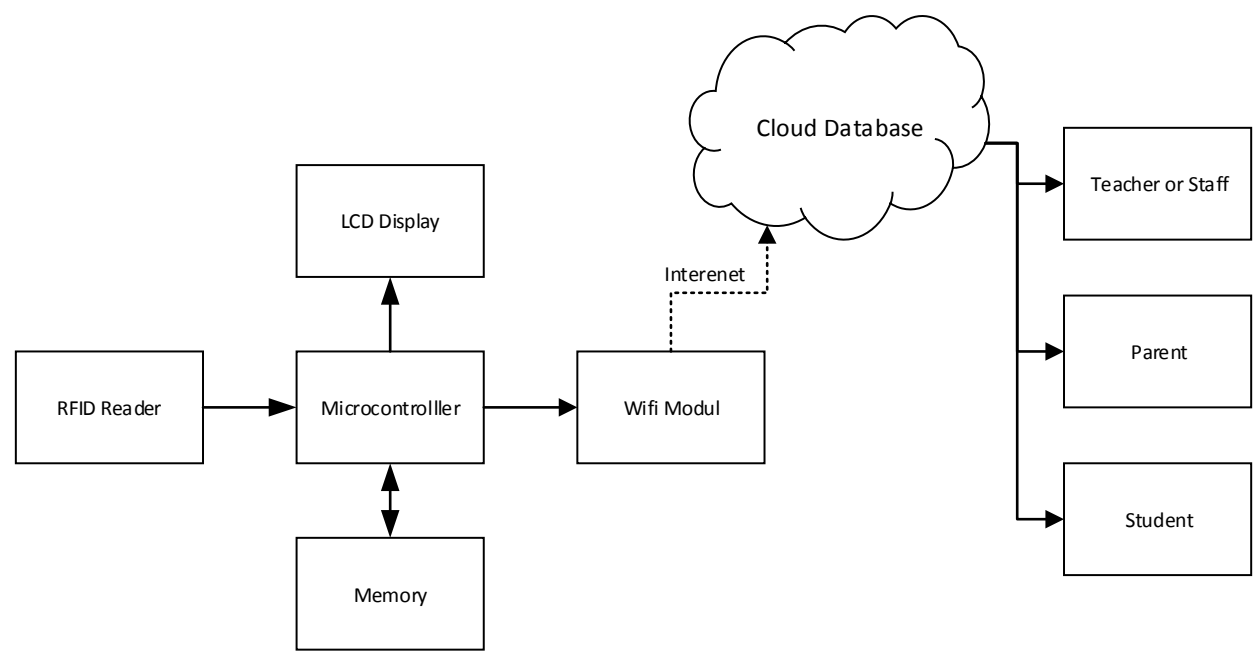

Fig. 3. Block diagram of attendance monitoring system.

Block diagram in Figure 3. Show that the process of attendance is done by using RFID technology, in this system each student has an RFID Tag to do presence, student put RFID Tag near RFID Reader, then ID result from RFID reader will be sent to microcontroller and compare it with the student data stored in memory, memory serves to store the data of the student's name of the course, if the data ID is a lecture participant then the student's name will be displayed on the LCD Display as well if the student data is not listed it will be informed through LCD Display that the student unregistered, using Wi-Fi module microcontroller can send student attendance data to cloud database by using internet network, data already accommodated in cloud database can be seen in real time by teacher, student and even parent, so that student presences can be monitored from anywhere in real time using Internet of Things (IoT).

\subsection{Flowchart presence using loT-based RFID}


Presence process as illustrated in the flowchart in Figure 4 starting from the RFID Tag scanning process using RFID Reader, the data obtained will be compared to the database, if the data match the database then the presence data will be stored in the cloud database, but if the data is not suitable then will be asked to scanning again RFID Tags, data stored in the cloud database is Student ID data, date and time of attendance, courses and on what week of attendance.

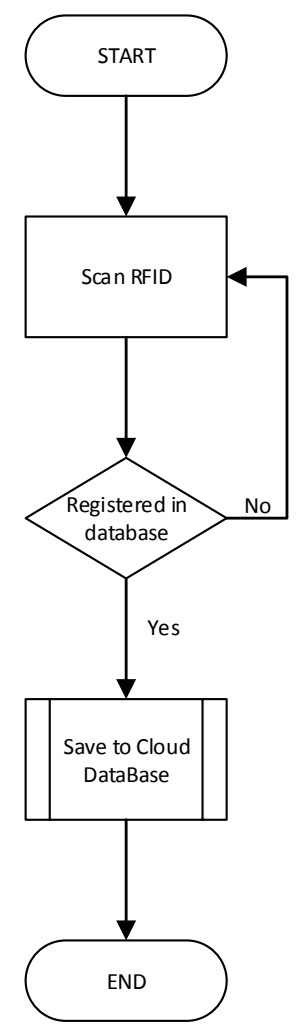

Fig. 4. Flowchart of RFID scan. 


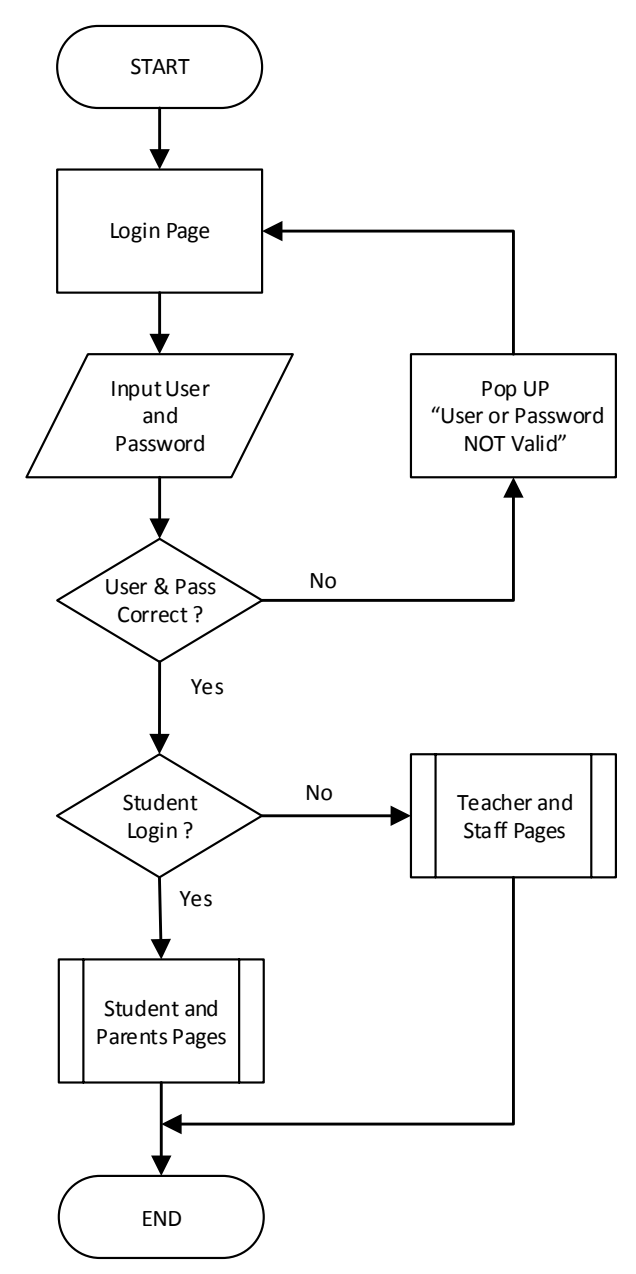

Fig. 5. Flowchart system

To display the results of presence data the user must login first, the login process determines the view that can be seen later, the user is divided into two kinds of login as a teacher or administration, and login as a student or parent, attendance data that has been stored in the cloud database can be displayed through two types of users, in Figure 6 is the output display for teachers and administration, where in this view attendance data from students are grouped by subject and class, while in Figure 7 is the output display for students and parents, it only displays data from students who login only, the name of the students displayed depending on the user's students and parents, so that each student and parents can only see their own presence data only. Figure 8 shows that the presence with RFID is faster than manual 


\section{Implementation and results}

In Figure 6, a list of students on a particular course for one semester is shown. From the list, the presence and absence of a student can be observed. For instance, the student at the top of the list is shown to be absent at the second week of computer networking courses.

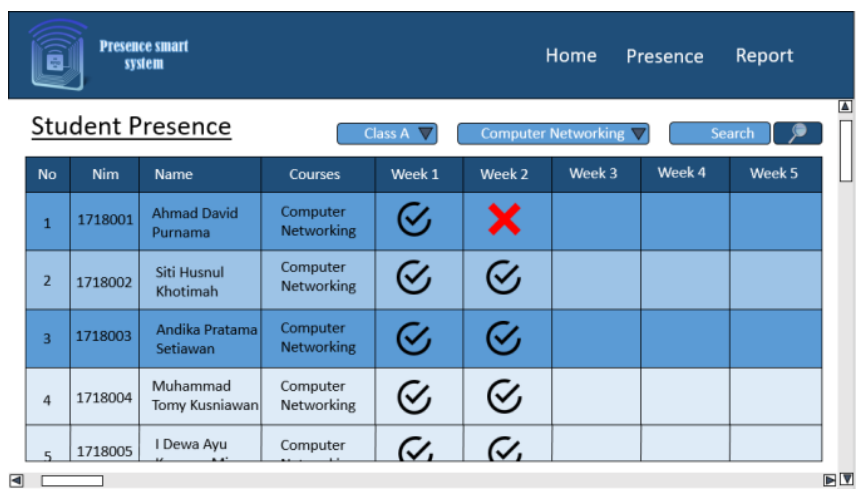

Fig. 6. Attendance list each subject and class for lecturer.

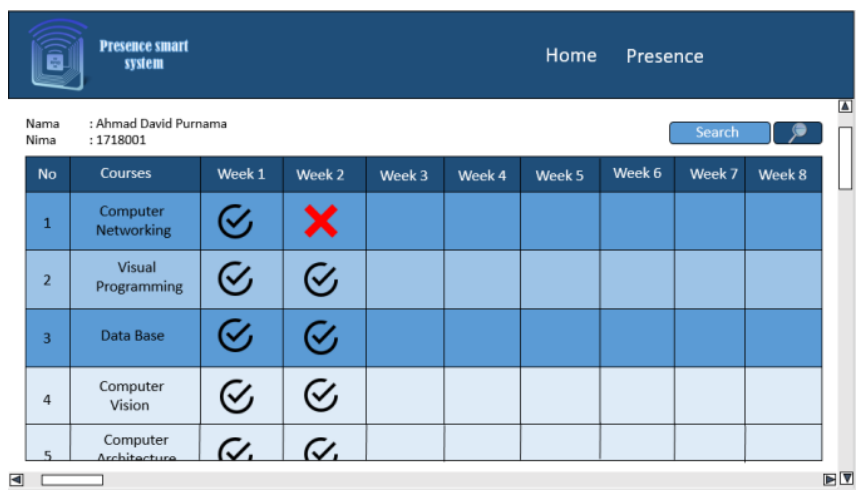

Fig. 7. Attendance list each student for student and parents.

Figure 7 displays a list of courses taken by a student along with his attendance for one semester. Through the list, the student's presence or absence can be observed on all courses he took. As shown in Figure 7, the student is absent during the second week of computer networking course. As for Visual Programming, Data Base and Computer Vision courses he is present in both, the first and second week. 


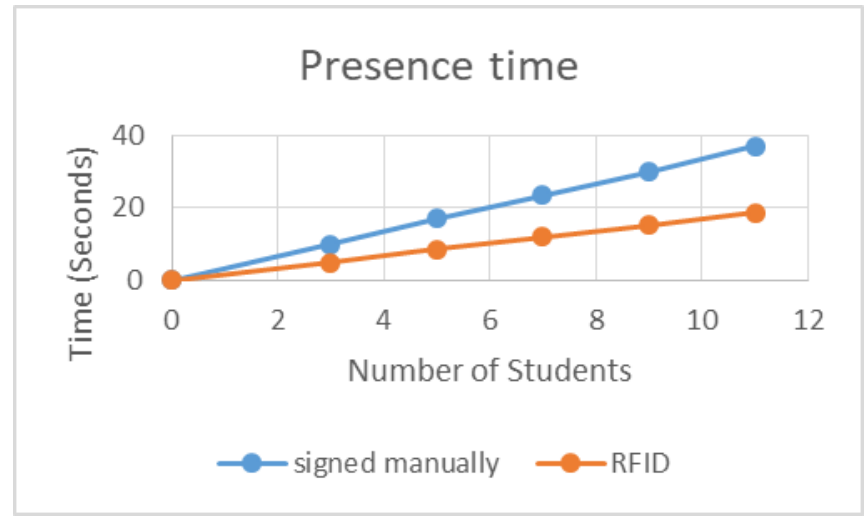

Fig. 8. Comparison of time attendance.

In Figure 8, it shows the comparison between the listing attendance manually and using RFID. The figure represents that using RFID, listing the attendance of 11 students took only $20 \mathrm{~s}$, whereas the manual method takes twice as long which is $40 \mathrm{~s}$.

\section{Conclusion}

From the test results can be concluded that the presence by using RFID faster than the traditional way and the implementation of the Internet system of things and data storage cloud enables the system to run in real time with accurate data.

\section{References}

1. S. Nainan, R. Parekh, T. Shah. IJCSI, 10,1(2013). https://arxiv.org/abs/1306.5381

2. K. Ding, P. Jiang. IEEE/CAA Journal of Automatica Sinica, 5,1 :128-138(2017). http://ieeexplore.ieee.org/document/7833265/

3. A. Singh, S. Meshram, T. Gujar, P.R. Wankhede. Baggage tracing and handling system using RFID and IoT for airports. International Conference on Computing, Analytics and Security Trends (CAST), (Pune, India, 2016).

http://ieeexplore.ieee.org/document/7915014/

4. T. Sharma, S.L. Aarthy. An automatic attendance monitoring system using RFID and IOT using Cloud. 2016 Online International Conference on Green Engineering and Technologies (IC-GET), (Coimbatore, India, 2016).

http://ieeexplore.ieee.org/document/7916851/

5. O.T. Arulogun, A. Olatunbosun, O.A. Fakolujo, O.M. Olaniyi. IJSER, 4,2:1-9(2013). https://www.ijser.org/researchpaper/rfid-based-students-attendance-managementsystem.pdf.

6. O.G., Chiagozie, O.G. Nwaji. Academic Research International, 2,2:168-183 (2012). https://www.researchgate.net/publication/280558358_RADIO_FREQUENCY_IDENT IFICATION_RFID_BASED_ATTENDANCE_SYSTEM_WITH_AUTOMATIC_DO OR UNIT

7. M. Kassim, H. Mazlan, N. Zaini, M.K. Salleh. Web-based student attendance system using RFID technology. IEEE Control and System Graduate Research Colloquium, 
(Selangor, Malaysia, 2012). ICSGRC:213-218(2012).

http://ieeexplore.ieee.org/document/6287164/

8. N. Saparkhojayev, S. Guvercin, IJCSI, 9,3:227-230(2012). http://citeseerx.ist.psu.edu/viewdoc/download?doi=10.1.1.401.8786\&rep=rep1\&type= pdf.

9. J.D. Irawan, S. Prasetio, S.A. Wibowo. IP based module for building automation system. In: Proceedings of second international conference on electrical systems, technology and information 2015 (ICESTI 2015). F. Pasila, Y. Tanoto, R. Lim, M. Santoso, N. Pah (Eds), Singapore: Springer (2016). pp. 337-343). https://link.springer.com/chapter/10.1007/978-981-287-988-2_36

10. H.M. Nguyen, S.H. Kim, D.T. Le, S. Heo, J. Im, D. Kim. Optimizations for RFIDbased IoT applications on the Cloud. 5th International Conference on the Internet of Things, (Seoul, South Korea, 2015). http://ieeexplore.ieee.org/document/7356551/

11. Z. Singhal, R.K. Gujral, International Journal of Computer Applications, 39,3:37-41 (2012). http://citeseerx.ist.psu.edu/viewdoc/download?doi=10.1.1.259.3846\&rep=rep1\&type= pdf 